\title{
Trabalho, Globalização e Antropologia
}

\author{
Trabajo, Globalización y Antropología \\ Work, Globalization and Anthropology
}

\author{
Dra. Rosana Eduardo da Silva Leal ${ }^{1}$
}

\begin{abstract}
Resumo
O trabalho é ainda uma das forças centrais da sociedade. Trata-se de um espaço simbólico em que perpassam relações de exploração, reivindicação, negociação, rede de solidariedade ou competição, apresentando-se também como campo em que dialogam saberes, ofícios, técnicas e tecnologias distintas. Para a Antropologia, o mundo do trabalho não se constitui apenas de valores pecuniários, pois oferece uma multiplicidade de produções culturais possíveis de serem estudadas. Os estudos antropológicos sobre o trabalho observam as formas de controle no recrutamento dos trabalhadores, as hierarquias construídas, o processo de qualificação transnacional e as formas de valorização e reconhecimento de ofícios tradicionais. Considera ainda os tipos de trabalho, as formas de rendimento e como estes interferem na vida social comunitária dos respectivos trabalhadores. Neste âmbito, o presente artigo tem como objetivo desenvolver um debate teórico sobre os caminhos percorridos pelo mundo do trabalho em tempos de globalização. Busca ainda estabelecer uma análise sobre o papel, os desafios e as contribuições da Antropologia na teorização e pesquisa sobre o tema. Diante do exposto, consideramos que o estudo do mundo do trabalho envolve situações extremas quando descortinam ambientes de desigualdades sociais, formas de exploração diversas (prostituição, trabalho infantil, trabalho escravo), bem como práticas discriminatórias e de exclusão, exigindo posicionamentos críticos, éticos e políticos do antropólogo.
\end{abstract}

Palavras-chave: Globalização; Antropología; Trabalho.

\section{Resumen}

El trabajo sigue siendo una de las fuerzas centrales de la sociedad. Es un espacio simbólico en el que permean las relaciones de explotación, reclamo, negociación, red solidaria o competencia, presentándose también como un campo en el que se dialogan diferentes conocimientos, artesanías, técnicas y tecnologías. Para la antropología, el mundo del trabajo no es solo de valores pecuniarios, sino que ofrece una multitud de producciones culturales que pueden estudiarse. Los estudios antropológicos sobre el trabajo observan las formas de control en la contratación de trabajadores, las jerarquías construidas, el proceso de calificación transnacional y las formas de valorar y reconocer las artesanías tradicionales. También considera los tipos de trabajo, las formas de ingreso y cómo afectan la vida social de sus trabajadores. En este contexto, el presente artículo tiene como objetivo desarrollar un debate teórico sobre los caminos tomados por el mundo del trabajo en tiempos de globalización. También busca establecer un análisis del papel, los desafíos y las contribuciones de la antropología en la teorización y la investigación sobre el tema. Dado lo anterior, consideramos que el estudio del mundo del trabajo involucra situaciones extremas cuando descubren ambientes de desigualdad social, diferentes formas de explotación (prostitución, trabajo infantil, trabajo esclavo), así como prácticas discriminatorias y excluyentes, que requieren posiciones críticas, éticas y éticas. Políticos del antropólogo.

Palabras claves: Globalización; Antropología; Trabajo.

\footnotetext{
${ }^{1}$ Doutora em Antropologia pela Universidade Federal de Sergipe; Coordenadora do Grupo de Pesquisa em Antropologia e Turismo - ANTUR/UFS/CNPQ; Docente do Departamento de Turismo e do Programa de PósGraduação Interdisciplinar em Culturas Populares da Universidade Federal de Sergipe; Brasil; e-mail: rosanaeduardo@yahoo.com.br.
} 


\begin{abstract}
Work is still one of the central forces of society. It is a symbolic space in which relations of exploitation, claim, negotiation, solidarity network or competition permeate, also presenting themselves as a field in which different knowledge, crafts, techniques and technologies dialogue. For anthropology, the world of work is not only of pecuniary values, it offers a multitude of cultural productions that can be studied. Anthropological studies on work observe the forms of control in the recruitment of workers, the built hierarchies, the process of transnational qualification and the ways of valuing and recognizing traditional crafts. It also considers the types of work, the forms of income and how they affect the social life of their workers. In this context, the present article aims to develop a theoretical debate on the paths taken by the world of work in times of globalization. It also seeks to establish an analysis of the role, challenges and contributions of anthropology in theorizing and research on the subject. Given the above, we consider that the study of the world of work involves extreme situations when they uncover environments of social inequality, various forms of exploitation (prostitution, child labor, slave labor), as well as discriminatory and exclusionary practices, requiring critical, ethical and ethical positions. anthropologist's politicians.
\end{abstract}

Keywords: Globalization; Anthropology; Work.

\title{
Introdução
}

Pensar antropologicamente as questões do mundo do trabalho em tempos de globalização é, antes de tudo, um risco. Primeiro porque as duas categorias, globalização e trabalho, já representam separadamente caminhos escorregadios para tal feito. E depois, porque a sua união produz interconexões teóricas e metodológicas difíceis de serem transitadas, justamente por pertencerem a universos tão amplos. Por isso, considero que o principal desafio deste artigo é produzir uma reflexão atenta aos detalhes sem perder a magnitude do todo, compartilhando do pensamento de Geertz (2001) quando diz que a maneira de refletir sobre o mundo está nitidamente menos clara.

As transformações ocorridas com as exigências do modelo transnacional de gestão e o uso de tecnologias de alto nível em empresas desterritorializadas têm influenciado os vários setores da economia mundial, como o setor do agronegócio brasileiro, por exemplo, responsável pela inserção de diversas regiões rurais no mercado capitalista transnacional. Este será durante todo o texto utilizado como elemento empírico para pensar o que teoricamente está sendo tratado.

\section{Economia globalizada}

Mesmo estando frequentemente presentes nos estudos sociológicos sobre o mundo do trabalho, o fordismo e o pós-fordismo como categorias analíticas por si só não dão conta das mudanças empreendidas na economia mundial nos últimos cinquenta anos, sobretudo pela 
variedade de práticas econômicas que envolvem a produção, a distribuição e o consumo em tempos de globalização. Bonnano (2004), que fez um profundo estudo sobre o tema, esclarece que o fordismo e o pós-fordismo não devem ser visualizadas como categorias estanques, sobretudo quando passam a ser utilizadas em estudos empíricos comparativos. O autor lembra ainda que tais modelos não possibilitam analisar todas as vertentes da globalização, pois são instrumentos voltados para o debate socioeconômico.

Com o uso de tecnologias comunicacionais e a redução dos custos de transporte, houve a compressão do espaço-tempo. Os avanços tecnológicos proporcionaram também o controle dos fatores de produção, ajudando a reduzir prejuízos e assegurar a qualidade final do produto, conforme exigências mundiais do mercado e dos consumidores. Assim, enquanto a flexibilização tinha por objetivo aumentar as vantagens coorporativas, financeiras e fiscais, que aceleravam a posição competitiva no mercado, a centralização de aspectos como finanças, pesquisas e informações possibilitaria a manutenção do poder hegemônico. Assim, tais modificações também influenciaram decisivamente no processo de produção das localidades receptoras.

O papel do Estado foi redefinido e minimizado. Anteriormente, o papel estatal era de regulador das atividades econômicas e mantenedor da soberania nacional, sendo capaz de criar barreiras para o trânsito livre em âmbito nacional. Mas no pós-fordismo transformou-se não só em facilitador do comércio neoliberal, mas também em coparticipante do trânsito das corporações transnacionais, na medida em que passou a minimizar as taxas fiscais para a instalação do capital internacional em seu território.

Os sistemas de produção flexível passaram a ter relação direta com as novas práticas do consumo e buscaram explorar nichos de mercado especializados e de pequena escala, passando a caminhar de mãos dadas com as modas fugazes, celebrando uma estética efêmera e mercantilizada (HARVEY, 1989). Assim, o pós-fordismo tornou-se um instrumento globalizador, que teve como meta diminuir ou dissolver a rigidez da economia mundial, através da desterritorialização de produtos, finanças, pessoas e informação. É o que Bonano (1999) denomina de hipermobilidade.

O conceito indica que há um potencial em nível global para a mobilidade e que a variedade de localidades e suas relações sociais (mercados de trabalho, forças de trabalho, instituições sociais) estão ligadas através dos processos de acumulação de capital e de reorganização espacial. As ligações das várias localidades ao redor do 
mundo redefinem a noção corrente do espaço local. A hipermobilidade determina a existência de localidades onde as estratégias globais se materializam.

Mas o autor explica ainda que os capitais não se movem igualmente e na mesma velocidade, pois dependem das facilidades ou dificuldades encontradas nos processos de transferências. $\mathrm{O}$ capital financeiro movimenta-se rapidamente, já que sua mobilidade depende de transações eletrônicas. O produtivo tem mais dificuldade em mover-se, pois sua mudança envolve outros fatores que influenciam seu movimento.

Um outro elemento que deve ser acrescentado diz respeito a compreensão do que seria considerada classe trabalhadora. No primeiro momento ela era predominantemente associada aos trabalhadores manuais, fabris que refletia a intrínseca relação com o ambiente das organizações fordistas. No segundo momento, que desemboca nos dias de hoje, tem-se a ampliação da compreensão dos que representam a classe trabalhadora, chamada por Antunes (2003, p.214-215) de "classe-que-vive-do-trabalho". Formada pela "[...] totalidade dos assalariados, homens e mulheres que vivem da venda de sua força de trabalho e são despossuídos dos meios de produção".

Neste cenário de instabilidade, as formas coletivas de organização dos trabalhadores passaram a ter seu espaço reduzido, tendo dificuldade em se organizar sindicalmente para reivindicar seus direitos. "Os novos tempos pareciam trazer um tipo de sociabilidade que se contrapunha a quaisquer possibilidade de participação de corte coletivo e público" (RAMALHO \& SANTANA, 2003, p.12).

A luta política dos sindicatos paulatinamente foi perdendo a sua força. Primeiro por conta da pressão exercida pelas estratégias de gestão interna, que diante da vulnerabilidade dos trabalhadores em relação ao desemprego, passaram a desestimular a mobilização sindical. E depois devido à amplitude global do respectivo empregador, que dispersou o terreno de negociação coletiva.

O enfraquecimento do sindicalismo também foi resultado da flexibilização das formas contratuais que reduziram o poder de organização das classes trabalhadoras, mas também da descentralização da produção e da mobilização da mão-de-obra. As organizações transnacionais passaram a se inserir nos países periféricos, por encontrarem facilidades fiscais e mão-de-obra barata, graças ao apoio do Estado-nação que migrou de regulador para facilitador do capital financeiro internacional. Assim, o caráter seletivo do mercado de 
trabalho ampliou o processo de exclusão social, atingindo de forma mais intensa alguns grupos que vem enfrentando barreiras para terem acesso a ele, como as minorias étnicas, as mulheres, os jovens, os idosos, os deficientes, entre outros. Frente às pressões dos mercados, os empresários passaram a desenvolver pressões sobre a mão-de-obra buscando aumentar a produtividade e a competitividade das organizações, através da redução de custo e outras estratégias.

As mudanças empreendidas pela tecnologia têm contribuído paulatinamente para a precariedade do trabalho. Tal realidade tem elevado as estatísticas de desemprego; o aumento da terceirização ou a contratação por tempo determinado e horas de trabalho reduzidas. A tecnologia alterou não só a divisão do trabalho, mas também o conteúdo das tarefas e o processo de qualificação profissional, redefinindo a concepção do sujeito enquanto trabalhador e empregado.

A formação profissional passou a ser exigida através de parâmetros externos de qualificação, reorientado as formas de gestão existentes. Tais medidas foram tomadas como exigências diante dos padrões de qualidade exigidos, para que os produtos pudessem circular livremente conforme padrões de qualidade no mercado mundial. A "qualidade total" passou a fazer parte do vocabulário da educação, formação e qualificação profissional, estando em comum acordo com as exigências das inovações tecnológicas e/ou organizacionais.

\section{A relação global e local}

Muitos países que adotaram programas macroeconômicos compatíveis com o paradigma pósfordista passaram a vivenciar, paradoxalmente, um quadro dramático de crescimento insuficiente de sua economia interna. Ao integrar-se as novas localidade e regiões, as cadeias produtivas globais passaram a interferir diretamente nas condições de desenvolvimento econômico e social, bem como nos padrões políticos de participação local. Os produtores familiares e os trabalhadores locais tornam-se os mais vulneráveis no processo de modernização produtiva e reestruturação econômica local, pois as novas estratégias de acumulação repercutem diretamente na estrutura social local e na vida dos atores sociais envolvidos. 
Neste âmbito, é possível perceber que há dois pesos e duas medidas quanto às restrições dos fluxos do capital produtivo. Enquanto nos países centrais o Estado adotou políticas restritivas em relação aos fluxos externos, como na agricultura por exemplo, nos países periféricos a expansão da macroeconomia neoliberal fragiliza e deteriora o trabalho do pequeno produtor, impactando nas atividades agropecuárias e agroindustriais locais.

$\mathrm{Na}$ intrínseca relação entre o global e local, observa-se que "[...] a lógica e dinâmica do capitalismo global é um poderoso instrumento acelerador dos efeitos marginalizadores, na sua maior parte provocado pela concentração produtiva nas zonas mais ricas com o consequente abandono das mais desfavorecidas" (MOREIRA, 2001, p.151).

O Brasil traz em sua constituição histórica um cenário de concentração e controle dos fatores de produção nas mãos de grupos privilegiados. Mas no contexto da globalização esse controle passou também a estar nas mãos das empresas transnacionais, que passam a influenciar na realidade local. Os pequenos produtores, que não possuem o controle dos bens de produção, são expostos a riscos maiores pela falta das tecnologias existentes, e quando buscam relacionar-se com o mercado internacional também sofrem com as exigências externas, visto que:

a) os parâmetros de produtividade e qualidade dos produtos agrícolas diferem dos exigidos pelo mercado transnacional. Há exigências tanto diante da qualidade dos produtos quanto no que se refere aos aspectos estéticos (embalagem, padronização, aparência, entre outros aspectos);

b) a forma de organização e gestão das pequenas propriedades diferem das estratégias utilizadas por empresas multinacionais. São pequenas unidades familiares, cujas formas de relacionamento divergem da anterior.

c) o padrão internacional exige mecanismos de análise de todas as etapas de produção e isso normalmente não acontece com os pequenos produtores.

O Nordeste tem sido um dos focos de intervenções do mercado internacional no Brasil. No setor primário tem-se o desenvolvimento do agronegócio para fins de exportação, estudado por diversos cientistas sociais. Cavalcanti (1997) faz um estudo sobre o processo de entrada do Vale do São Francisco no mercado internacional, através da produção frutícola destinada à exportação. Em todo o texto da referida autora há a análise de como o padrão de qualidade 
global tem interferido e modificado as relações de trabalho, as estratégias de gestão de empreendimentos, bem como a produção de mercadorias locais. É possível perceber também as influências exercidas pela globalização no que se refere às formas de participação política dos trabalhadores, nos mecanismos de qualificação e na distinta divisão sexual de trabalho. A autora ressalta que,

É importante assinalar que a adaptação da produção aos novos ritmos e espaços que se ampliam com a abertura de mercados e com os novos acordos de integração regional entre países, requer relações entre capital e trabalho redefinidas; isso significa uma participação coletiva dos distintos atores nas diferentes fases do processo produtivo e, ainda mais, uma responsabilidade coletiva na qualidade final do produto. Perseguir um padrão de qualidade significa coordenar e organizar eficientemente tempo, conhecimento, tecnologia e recursos humanos. Produtores e trabalhadores devem estar preparados para as novas práticas de gestão e outras tarefas especializadas agora requeridas (CAVALCANTI, 1997, p.85).

O contexto da cana-de-açúcar também permite ilustrar as interfaces entre o global e o local. O aumento do interesse do capital internacional no agronegócio de açúcar e do álcool tem estimulado a chegada de grupos internacionais no Brasil e a migração de usinas nordestinas tradicionais para o eixo Sudeste/Centro-Oeste (OLIVEIRA, 2007). Os contratos provisórios de trabalhadores produzem migrações temporárias para a área de produção, como ocorre com muitos nordestinos que trabalham no corte da cana-de-açúcar no estado de São Paulo.

No trabalho na cana-de-açúcar há um intenso uso da massa trabalhadora, que é utilizada sobretudo no corte manual que é realizado em períodos que variam de oito a doze horas por dia. Os trabalhadores são provenientes de vários estados nordestinos, como Maranhão, Rio Grande do Norte, Piauí e Paraíba, que migram temporariamente e deixam suas famílias por cerca de cinco a sete meses. O êxodo dos trabalhadores nordestinos para outras regiões brasileiras não é novidade, mas atualmente traz traços distintos do que ocorria anteriormente.

As condições trabalhistas são precárias e os problemas de saúde são constantes, justamente pelo intenso ritmo de trabalho ao qual tais trabalhadores estão expostos. Conforme o economista e pesquisador José Roberto Novaes ${ }^{2}$, as usinas tem critérios bem claros para a definiçãa do perfil de seus funcionários. O primeiro é que os trabalhadores estejam entre 18 e 29 anos - faixa etária considerada ideal para o desenvolvimento das tarefas diárias. Depois,

2 NOVAES, José Roberto. $O$ drama dos cortadores de cana. Disponível em: <http://www.cptpe.org.br/modules.php?name=News\&file=print\&sid=105>. Acesso em: 28. 05.2008. 
que sejam preferencialmente migrantes para que se possam ter maior controle sobre a vida dos trabalhadores. E por último, que sejam prioritariamente do sexo masculino.

O reordenamento das empresas do agronegócio canavieiro que migraram de estados nordestinos para outras regiões brasileiras sem expressão nacional no plantio da cana, provocou mudanças na dinâmica de trabalho tanto das regiões tradicionalmente produtoras quanto das que são áreas receptoras. Trata-se de um cenário social, econômico e cultural complexo e dinâmico para se pensar as configurações dos espaços produtivos no processo da globalização.

\title{
3. A globalização como temática antropológica
}

A globalização pode ser considerada como um processo histórico-social que abala o mundo, na medida em que inaugura processos distintos de economia, sociabilidade, comunicação e locomoção, envolvendo indivíduos e coletividades.

\begin{abstract}
Muito do que parecia estabelecido em termos de conceitos, categorias ou interpretações, relativos aos mais diversos aspectos da realidade social, parece perder significado, tornar-se anacrônico ou adquirir outros sentidos. Os territórios e as fronteiras, os regimes políticos e os estilos de vida, as culturas e as civilizações parecem mesclar-se, tensionar-se e dinamizar-se em outras modalidades, direções ou possibilidades. As coisas, as gentes e as idéias movem-se em múltiplas direções, desenraizam-se, tornam-se volantes ou simplesmente desterritorializam-se (IANNI, 1998, p.01).
\end{abstract}

Mas o desenvolvimento de uma ordem econômica globalizada acelerou-se a partir de meados dos anos 1980 com a intensificação das interações transnacionais, que envolveu sistemas produtivos, transferências financeiras, fluxos informacionais e de pessoas.

Nas palavras de Giddens (1991, p, 69), “a globalização pode assim ser definida como a intensificação das relações sociais em escala mundial, que ligam localidades distantes de tal maneira que acontecimentos locais são modelados por eventos ocorrendo a muitas milhas de distância e vice-versa”. A sugestão de Appadurai (1998) é pensar a globalização através dos fluxos que a constitui, denominados como:

Etnopanoramas: panorama de pessoas ou grupos que se ocupam com realidades de ter de se movimentar, tais como turistas, imigrantes, refugiados, exilados, àqueles 
que trabalham fora do país, entre outros. Esses públicos afetam a política entre as nações num grau sem precedentes;

$\checkmark$ Tecnopanoramas: trata-se da tecnologia que se movimenta em alta velocidade sem as barreiras que antes eram intransponíveis;

$\checkmark$ Finançopanoramas: onde ocorre a distribuição de capital global.

$\checkmark$ Midiapanoramas: referem-se à distribuição e disseminação de informações, narrativas e imagens midiáticas;

$\checkmark$ Ideopanoramas: as imagens relacionadas às ideologias dos estados ou das contraideologias que buscam tomar o poder.

Como objeto de estudo antropológico, a globalização ainda é vista com resistência e cautela. Conforme Velho (1997), o próprio cenário de descolonização propiciou uma posição incômoda na disciplina, sobretudo pelas críticas a ela direcionadas, que corroboraram para sua discreta inserção em debates sobre o tema. $\mathrm{O}$ autor explica que no processo de intensificação da globalização, a posição tomada pela Antropologia foi de manter um debate romântico, posicionando-se como um contra discurso em favor dos nativos e das culturas, que ia de encontro às ideologias da modernidade. Mas essa postura conservadora da disciplina produziu críticas importantes sobre os estudos simplistas e unilaterais que privilegiavam a visão macro desta realidade, alertando para os perigos políticos e ideológicos causados por tais tratamentos.

Ao que se parece, a autorreflexão da disciplina tem se dado menos pela globalização em si do que pela mudança de postura dos interlocutores, que substituíram muitas das suas práticas tradicionais e passam a viver em outras localidades, o que levou a disciplina a ver com desconfiança as totalidades fechadas e os conceitos reificados, uma que estes não davam mais conta do ambiente empírico.

\section{Trabalho e Antropologia: algumas discussões}

O trabalho é ainda uma das forças centrais da sociedade. Trata-se de um espaço simbólico em que perpassam relações de exploração, reivindicação, negociação, rede de solidariedade ou competição, apresentando-se também como campo em que dialogam saberes, ofícios, técnicas e tecnologias distintas. Para a Antropologia, o mundo do trabalho não se constitui apenas de 
valores pecuniários, pois oferece uma multiplicidade de produções culturais possíveis de serem estudadas.

No estudo sobre o trabalho, a Antropologia possibilita contemplar ambientes culturais distintos e o cotidiano dos povos tradicionais e mercantis, que envolvem economias formais, informais e domésticos. Seu estudo traz ganhos significativos para a disciplina, na medida em que contribui para a compreensão das transformações vividas no plano social, conforme observa Durão \& Marques (2001, p.66):

[...] os espaços sociais e sócio-técnicos de trabalho são, além de particularmente densos do ponto de vista social e cultural, cada dia mais abertos a dinâmicas globais. Parece ajustado pensar-se que não só o estudo do trabalho reclama a contribuição da antropologia, como esta tem a ganhar, na sua compreensão do social, em construir e aprofundar um tal objecto.

O mundo do trabalho está perpassado por relações de poder, de prestígio, de submissão e/ou rejeição, sendo influenciado por categorias como classe social, etnia e gênero. Como salienta Cavalcanti (2004), é necessário estar atento também para os símbolos, habitus e significados culturais embutidos neste universo, que envolve indivíduos e sociedades, espaços físicos e sociais.

Os estudos antropológicos sobre o trabalho observam as formas de controle no recrutamento dos trabalhadores, as hierarquias construídas, o processo de qualificação transnacional e as formas de valorização e reconhecimento de ofícios tradicionais. Considera ainda os tipos de trabalho, as formas de rendimento e como estes interferem na vida social comunitária dos respectivos trabalhadores. Quando observa as relações laborais, a disciplina distancia-se da naturalização do discurso hegemônico sobre a classe trabalhadora e busca aprofundar o conhecimento sobre as redes sociais, as construções subjetivas sobre o emprego e a capacidade de resistência e de negociação dos agentes sociais envolvidos. Alguns temas que envolvem o mundo do trabalho têm ganhado força neste âmbito, como é o caso das questões de gênero, do setor informal, dos fluxos migratórios e da relação global-local.

Sobre a questão de gênero, os estudos antropológicos têm buscado entender como se processa a divisão sexual de trabalho, concentrando suas observações no trabalho feminino. Muitos estudos buscam compreender a inserção das mulheres no mercado de trabalho, considerando também o ambiente doméstico. Aspectos como atividades ocupacionais, parâmetros de remuneração, barreiras ou facilidades ligadas ao gênero também são contemplados em tais estudos. 
Ribeiro (2007) chama atenção para a globalização popular, que se apresenta como um importante tópico para as ciências sociais, por permitir identificar formas de apropriações e reelaborações produzidas pelos atores populares periféricos diante dos fluxos globais. A relação entre os fluxos migratórios e a cadeia produtiva de países centrais também fazem parte da agenda de discussão antropológica, sobretudo pelo papel econômico, demográfico, político e cultural que representam, bem como da influência gerada por tais fluxos tanto na dinâmica do local de origem, como também do território em que vivem e trabalham.

A questão da mobilidade, dos fluxos e das culturas em constante movimento tem configurado como categorias presentes nos estudos antropológicos sobre globalização. Antropólogos como Ulf Hannerz, Arjun Appadurai, James Clifford, e Marc Augé tem dado considerável atenção a esses aspectos em suas discussões sobre a contemporaneidade.

\section{Conclusões}

A globalização constitui um importante campo de estudo da Antropologia, na medida em que evidencia fluxo humanos, tecnológicos, financeiros, midiáticos e ideológicos. Esses fluxos remetem à necessidade de estudar as práticas socioculturais e econômicas na relação globallocal, considerando as dimensões políticas, identitárias e étnicas, bem como os embates e assimetrias existentes. Tal cenário repercute diretamente no âmbito dos estudos sobre o trabalho, que evidenciam muitas vezes precariedades e subalternidades, como ocorre no contexto do agronegócio para exportação presente no Nordeste brasileiro. Há também o campo das globalizações populares em que estão situados processos não-hegemônicos de trabalho e circulação de indivíduos, mercadorias e finanças presentes nas mais distintas localidades e mercados globais.

Neste âmbito, consideramos que o processo de reestruturação do trabalho tem sido objeto de estudo em diversas áreas, justamente pela vocação interdisciplinar que o tema representa. Tais enfoques são de suma importância para a academia e para a sociedade, na medida em que possibilitam ampliar as percepções sobre as transformações que vem ocorrendo. Mas é necessário ter em mente que tais reflexões não podem priorizar um ou outro polo (global ou local). Por isso, considero que uma das principais contribuições do enfoque antropológico está 
em equilibrar a balança de compreensão sobre o tema, na medida em que dá visibilidade e voz aos diversos atores sociais envolvidos, valorizando a interação entre eles.

O estudo do mundo do trabalho muitas vezes envolve situações extremas quando descortinam ambientes de desigualdades sociais, formas de exploração diversas (prostituição, trabalho infantil, trabalho escravo), bem como práticas discriminatórias e de exclusão, exigindo posicionamentos críticos, éticos e políticos do antropólogo. Mas a disciplina tem o desafio de buscar mecanismos metodológicos e categorias analíticas que deem conta das transformações que estão em curso e das mobilidades que seguem dando base à globalização.

Com a redução substantiva dos postos de trabalho formais, é possível também se debruçar sobre o universo informal de produção, distribuição e consumo, que proporciona a identificação de ações coletivas e individuais que reconfiguram o sentido de empregabilidade. E que fogem dos parâmetros da estrutura oficial vigente, possibilitando entender estratégias e construções de outras globalizações não-hegemônicas tão comuns em nosso cotidiano.

\section{Referências bibliográficas}

ABRAMO, LAÍS. Desafios atuais da sociologia do trabalho na América Latina: Algumas hipóteses para a discussão. En publicacion: Los retos teóricos de los estudios del trabajo hacia el siglo XXI. Enrique de La Garza Toledo. CLACSO, 1999.

ANTUNES, Ricardo. A nova morfologia do trabalho e o desenho multifacetado das ações coletivas. In: RAMALHO, José Ricardo \& SANTANA, Aurélio. Além da fábrica: trabalhadores, sindicatos e a nova questão social. São Paulo: Boitempo, 2003, p.179-212.

APPADURAI, Arjun. "Disjunção e diferença na economia cultural global” In: Featherstone, Mike (coord.). Cultura Global: nacionalismo, globalização e modernidade. 2.ed. Petrópolis, RJ: Editora Vozes, 1998, p.311-327.

BENDINI, Mônica. Entre maçãs y pêras: globalização, competitividade e trabalho. In: CAVALCANTI, Josefa Salete B.(org.) Globalização, Trabalho, Meio Ambiente: Mudanças socioeconômicas em regiões frutícolas para exportação. INPSO, Instituto de Pesquisas Sociais, FUNDAJ, Fundacao Joaquim Nabuco, Recife, Pernambuco, Brasil, 2004. Disponível em: <http://sala.clacso.org.ar〉. Acesso em: 25.05.08. 
BEYNON, Huw. O sindicalismo tem futuro no século XXI? In: RAMALHO, José Ricardo \& SANTANA, Aurélio. Além da fábrica: trabalhadores, sindicatos e a nova questão social. São Paulo: Boitempo, 2003, p.44-71.

BONANNO, Aessandro. A globalização da economia e da sociedade: fordismo e pósfrodismo no setor agroalimentar. In: CAVALCANTI, Josefa Salete B.(org.) Globalização, Trabalho, Meio Ambiente: Mudanças socioeconômicas em regiões frutícolas para exportação. INPSO, Instituto de Pesquisas Sociais, FUNDAJ, Fundacao Joaquim Nabuco, Recife, Pernambuco, Brasil, 2004. Disponível em: 〈http://sala.clacso.org.ar〉. Acesso em: 25.05.08.

CAVALCANTI, Josefa Salete B. Globalização e processos sociais na fruticultura de exportação do vale do São Francisco. In: CAVALCANTI, Josefa Salete B.(org.) Globalização, Trabalho, Meio Ambiente: Mudanças socioeconômicas em regiões frutícolas para exportação. INPSO, Instituto de Pesquisas Sociais, FUNDAJ, Fundação Joaquim Nabuco, Recife, Pernambuco, Brasil, 2004. Disponível em: <http://sala.clacso.org.ar>. Acesso em: 25.05.08.

CAVALCANTI, Josefa S. B. Frutas para o mercado global. São Paulo: Estudos avançados. Vol 11, n.29. Abr. 1997.

CLIFFORD, James. Dilemas de la Cultura: antropóloga, literatura y arte em la perspectiva posmoderna. Barcelo: GEDISA, 2001.

COPANS, Jean; GODELIER, Maurice; TORNAY, Serge; BACKES-CLEMENT, Catherine. Antropologia. Ciências das Sociedades Primitivas? Lisboa, Edições 70, p.21-56.

GEERTZ, Cliffod. Nova luz sobre a Antropologia. Rio de Janeiro: Jorge Zahar, 2001, p.191228.

GIDDENS, Anthony. As consequências da modernidade. São Paulo: Editora UNESP, 1991.

GODELIER, Maurice. $O$ ocidente, espelho partido: uma avaliação parcial da antropologia social, acompanhada de algumas perspectivas. RCBS. n 21, ano 08, fev. de 1993. p. 05-21.

HARVEY, David. Condição pós-moderna. 14ª ed. São Paulo: Ed. Loyola, 1992.

IANNI, Octavio. As ciências sociais na época da globalização. Revista Brasileira de Ciências Sociais. vol.13, n.37, São Paulo, junho, 1998.

MACHADO, Rosana Pinheiro. "A garantia soy yo": etnografia das práticas comerciais entre camelôs e sacoleiros nas cidades de Porto Alegre (Brasil) e Ciudad Del Este (Paraguai). Dissertação apresentada no Programa de Pós-Graduação em Antropologia Social da Universidade Federal do Rio Grande do Sul. Porto Alegre, 2004, 143 p. 
MAYBURY-LEWIS, David. A antropologia numa era de confusão. RBCS, Vol.17, $\mathrm{n}^{\circ} 50$. outubro/2002.

MOREIRA, Manuel Belo. Globalização e Agricultura: zonas rurais desfavorecidas. Oeiras: Celta,2001.

NOVAES, José Roberto.O drama dos cortadores de cana. Disponível em: <http://www.cptpe.org.br/modules.php?name=News\&file=print\&sid=105>. Acesso em: 28. 05.2008 .

OLIVEIRA, Ana Maria Soares. O processo de reordenamento territorial e produtivo do capital agroindustrial canavieiro e a nova geografia do trabalho migrante no Brasil. In: VII Jornada do Trabalho. Modernidade e os Signos da Civilização da Barbárie para a Classe Trabalhadora. Centro de Geografia do Trabalho - CEGeT (Universidade Estadual Paulista/UNESP). São Paulo, de 29 à 31 de outubro de 2007. Disponível em: <http://www4.fct.unesp.br/ceget/viiijornada.htm>. Acesso em: 28.05.08.

RAMALHO, José Ricardo \& SANTANA, Aurélio. Trabalhadores, sindicatos, e a nova questão social. In: RAMALHO, José Ricardo \& SANTANA, Aurélio. Além da fábrica: trabalhadores, sindicatos e a nova questão social. São Paulo: Boitempo, 2003, p.11-43.

RAMALHO, José Ricardo. Novas conjunturas industriais e participação local em estratégias de desenvolvimento. Dados, Rio de Janeiro, v. 48, n. 3, 2005. Disponível em: <http://www.scielo.br>. Acesso em: 29 May 2008.

RIBEIRO, Gustavo Lins. Antropologias mundiais. Para um novo cenário global na Antropologia. RBS, vol.21.n.60, fevereiro, p.-147-165.

RIBEIRO, Gustavo Lins. El sistema mundial no-hegemónico y la globalización popular. Série Antropologia - 410. Brasília, 2007. Disponivel em: <http:// www.unb.br/ics/dan/Serie410empdf.pdf>

SAHLINS, Marshall. O "pessimismo sentimental e a experiência etnográfica: por que a cultura não é um objeto em via de extensão" (Parte I). Mana. Rio de Janeiro, v.03, n.01, 1997.

SANTOS, Boaventura de Sousa Santos. Os processos da globalização. In: SANTOS, Boaventura de Sousa Santos (org.). A globalização e as Ciências Sociais. $2^{\text {a }}$ ed. São Paulo: Cortez, 2002, p. 25-102.

VELHO, Otávio. Globalização: Antropologia e Religião. Mana 3(1), 1997, p.133-154. 